\title{
Detection of COPB2 as a KRAS synthetic lethal partner through integration of functional genomics screens
}

\author{
Eleni G. Christodoulou ${ }^{1,2}$, Hai Yang ${ }^{3}$, Franziska Lademann $^{4}$, Christian Pilarsky ${ }^{3,4}$, \\ Andreas Beyer ${ }^{1,5}$, Michael Schroeder ${ }^{1}$ \\ ${ }^{1}$ Biotechnology Center, TU Dresden, Dresden, Germany \\ ${ }^{2}$ Department of Medical Oncology, National Cancer Center of Singapore, Singapore \\ ${ }^{3}$ Chirurgische Klinik, Translational Research Center, Universitätsklinikum Erlangen, Erlangen, Germany \\ ${ }^{4}$ Medizinische Fakultät Carl Gustav Carus, TU Dresden, Dresden, Germany \\ ${ }^{5}$ Cellular Networks and Systems Biology, University of Cologne, Cologne, Germany \\ Correspondence to: Andreas Beyer, email: andreas.beyer@uni-koeln.de \\ Michael Schroeder, email: ms@biotec.tu-dresden.de
}

Keywords: KRAS, synthetic lethal partner, ranking, rank aggregation, functional screens

Received: March 09, $2016 \quad$ Accepted: March 01, $2017 \quad$ Published: March 10, 2017

Copyright: Christodoulou et al. This is an open-access article distributed under the terms of the Creative Commons Attribution License (CC-BY), which permits unrestricted use, distribution, and reproduction in any medium, provided the original author and source are credited.

\section{ABSTRACT}

Mutated KRAS plays an important role in many cancers. Although targeting KRAS directly is difficult, indirect inactivation via synthetic lethal partners (SLPS) is promising. Yet to date, there are no SLPs from high-throughput RNAi screening, which are supported by multiple screens. Here, we address this problem by aggregating and ranking data over three independent high-throughput screens. We integrate rankings by minimizing the displacement and by considering established methods such as RIGER and RSA.

Our meta analysis reveals COPB2 as a potential SLP of KRAS with good support from all three screens. COPB2 is a coatomer subunit and its knock down has already been linked to disabled autophagy and reduced tumor growth. We confirm COPB2 as SLP in knock down experiments on pancreas and colorectal cancer cell lines.

Overall, consistent integration of high throughput data can generate candidate synthetic lethal partners, which individual screens do not uncover. Concretely, we reveal and confirm that COPB2 is a synthetic lethal partner of KRAS and hence a promising cancer target. Ligands inhibiting COPB2 may, therefore, be promising new cancer drugs.

\section{INTRODUCTION}

\section{$K R A S$ and cancer}

KRAS (Kirsten rat sarcoma viral oncogene homolog) is a protooncogene, whose constitutive activation through point mutations drives the neoplastic transformation in many cancers. Somatic KRAS mutations are frequent inleukemia, ovarian, colon, thyroid and lung cancers [1]. $K R A S$ is one of the most frequently activated oncogenes, with 17 to $25 \%$ frequency among all human tumors. $90 \%$ of pancreatic tumors harbor an activating KRAS mutation. KRAS is a small GTPase molecule, which acts as a GTP to GDP converter in its wild type state. When KRAS is in its active or GTP-bound state, it contributes to the propagation of growth factor signals from the extracellular environment to the nucleus. Growth factors are responsible for stimulating processes important to the cell, such as growth, proliferation, healing, and differentiation. Normally, KRAS is inactivated again by GAP. However, mutated KRAS loses this capability and remains locked in its active state. Upon activation, $K R A S$ drives the RAS-MAPK pathway leading to uncontrolled proliferation. $K R A S$ is considered to be largely undruggable [2,3] and despite recent successes [4] patients with $K R A S$ mutations still have very poor prognosis.

Synthetic lethality

Due to the difficulty of directly inhibiting $K R A S$, it has been proposed to repress its synthetic lethal partners [5]. Two genes are synthetic lethal if their simultaneous perturbation results in death, whereas a perturbation of just one of the two 
does not [6]. Concretely, a synthetic lethal partner (SLP) of $K R A S$ is lethal to the cell if the cell has mutated KRAS, but it is not lethal in a cell with wild-type $K R A S$.

Therapeutic strategies leveraging synthetic lethality have recently been brought to clinical trials with encouraging first results [5]. The most promising ex-ample is the synthetic lethal interaction of PARP and BRCA1/ $B R C A 2$ in cases of ovarian and breast cancer, which was very successful in phase II clinical trials [7]. Another study has recently demonstrated success in simultaneously targeting two genes interacting with KRAS [8], which further increases the complexity of the search space for new treatment options.

\section{RNAi screens for KRAS SLPs show little overlap}

In the past, several knock-down approaches identified candidate KRAS SLPs (e.g. [9-14]; see Supplementary Information for a complete list). Conceptually, all of these screens are similar: several genes in cells with and without activating KRAS mutations are knocked-down and then screened for inhibitions that preferentially kill KRAS mutated cells. The major limitation of this approach is the inconsistency between the experimental results. Supplementary Table 1 lists some 70 KRAS SLPs, but there is no SLP confirmed by all of the screens and studies. A mere seven SLPs (proteasome components $A P C / C, P S M A 5, P S M B 5$, PSMB6 and PSMD14, as well as BIRC5, and GATA2) are shared between two studies. Such inconsistencies arise due to the use of cell lines with different genetic backgrounds, use of different RNAi libraries, or due to different assays for quantifying the SLP phenotype. For example, different RNAi constructs targeting the same genes could differ with respect to their off-target effects $[15,16]$, leading to deviating phenotypes.

\section{Robust SLPs though consistent data integration across screens}

Despite these inconsistencies, we hypothesize that a consistent aggregation and re-ranking can lead to SLP candidates, which are supported by multiple screens and are hence more robust. Therefore, we set out to combine results from multiple screens using a computational framework that specifically identifies genes consistently showing SLP effects across screens. The framework accounts for variable sizes of the screens (numbers of genes targeted), variable numbers of cell lines used, and different noise levels in the screens and is therefore robust. Consider Figure 1: First, we identify three relevant screens and normalize and rank screens individually. Second, we find 1069 genes common to all three screens. Third, we integrate the three rankings minimizing overall displacements of genes. Forth, we combine the aggregated ranking with other, established methods (Riger and RSA) leading to a robust prediction consistent across screens and consistent across methods. Finally, the prediction is experimentally validated.

\section{RESULTS}

\section{Selected screens with minimal experimental variation share 1069 genes}

Three large-scale RNAi screens were selected for prioritizing robust SLP candidate genes [10-12] (see Table 1 [10-12] and Figure 1).

Subsequently, we refer to these screens based on their first author's names as Luo, Wang, and Steckel. These screens were chosen because they were performed on isogenic cell lines, which minimizes variance due to the genetic background, and because all cell lines originate from colorectal cancer with a G13D mutation, which further increases the similarity of the targeted cells. The Luo and Wang screens measured the impact of 1-15 (average 3 ) and 3 independent shRNAs per gene, respectively. Steckel, on the other hand, measured the impact of pools of 4 siRNAs per gene on caspase activity as a readout for apoptosis. Hence, whereas the Luo and Wang screens provide one cell viability score per shRNA (i.e. multiple per gene), the Steckel screens only reports one value per gene. Further, the Luo and Wang screens were performed in three replicates each, whereas only one replicate per gene is available from the Steckel screen (Table 1). All subsequent analyses were performed using the 1069 genes commonly targeted by all three screens. Due to the gene selection in the original screens, these 1069 genes are enriched for druggable kinases and for known cancer genes. Data from the Luo and Steckel screens had already been normalized by the authors using the mean and median absolute deviation (MAD), respectively. Data from the Wang screen were normalized by us using MAD [17]. Subsequently, individual gene scores were computed as follows.

In the case of the Steckel screen, where only summarized per sample and per gene measurements are available, we selected the genes that induce a $K R A S$ mutant cell specific apoptosis rate, which is higher than the median $+1 K R A S$-mutant apoptosis rate. In case of the other two screens, where replicates were available, we computed the average difference in cell viability between $K R A S$ mutants and KRAS wild type cells (averaged across siRNA constructs) and determined the significance of that difference using the paired $t$-test. We refer to this initial data processing as Standard Method. More details are provided in the Methods section.

\section{Poor consistency between screens}

As discussed above, the three screens have a similar experimental set- up and they all aim to find SLPs of the 
Table 1: RNAi datasetes

\begin{tabular}{|c|c|c|c|c|}
\hline Author & Genes & Isogenic & Cell lines & \\
\hline Luo, Cell, 2009 [10] & 19569 & 2 isogenic & $\begin{array}{l}\text { DLD1 } K R A S^{+/-} \\
\text {DLD1 } K R A S^{+/ \mathrm{G} 13 \mathrm{D}} \text { mutant }\end{array}$ & wild-type \\
\hline Steckel, Cell Res., 2012 [11] & 7283 & 2 isogenic & $\begin{array}{l}\text { HKE3 } \\
\text { HCT116 KRAS }\end{array}$ & wild-type \\
\hline Wang, Oncogene, 2010 [12] & 1740 & 2 isogenic & $\begin{array}{l}\text { HKE3 } \\
\text { HCT116 KRAS }\end{array}$ & wild-type \\
\hline
\end{tabular}

Three RNAi screens for $K R A S$ synthetic lethal partners serve as base for the present meta analysis.

G13D KRAS mutation. Yet, when ranking the screens individually using the Standard method (see Methods), there is poor agreement. The three screens share only three genes (BACH2, FOS, COPB2) within the top $10 \%$ of their rankings. Among any two screens there are between 15 to 66 genes in common. In fact, only the intersection of the Luo and Wang screen is significant ( $p$-value of 0.0123 , Fisher's exact test). The intersections of Luo/Steckel and Wang/Steckel are not better than chance ( $p$-value greater 0.08 , Fisher's exact test). The slightly better $p$-value for Luo/Wang might result from replicate measurements, which likely improved the stability of the results. Nonetheless, the screens do not agree.

\section{Luo ranks known SLPs high, steckel and wang don't}

In order to further evaluate the quality of the screens we assembled 28 known SLPs from literature
1

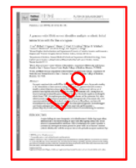

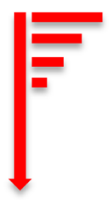
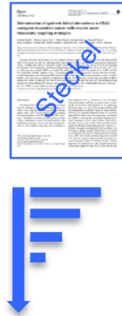
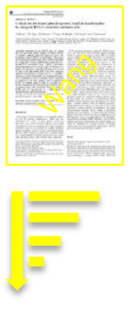

2

(Supplementary Table 1). 21 of these SLPs were common to all three screens and are subsequently referred to as 'Gold Standard Genes' (GSGs). We investigated the ranking of these GSG in each screen (Figure 2). In a successful screen, GSGs should rank high. However, Luo was the only screen enriching GSGs at the top of the list. These findings further underline the considerable variability inherent in the screens.

\section{Rank aggregation with spearman's footrule}

Consider Figure 1. In the third step, the three selected screens are aggregated. In order to obtain such an aggregated gene ranking that is maximally consistent between the screens, we re-rank the genes such that the deviation of the aggregated ranking is minimal with respect to the three original rankings. Here, we use Spearman's footrule to quantify differences between rankings.

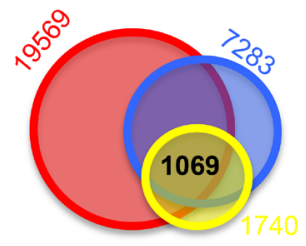

4

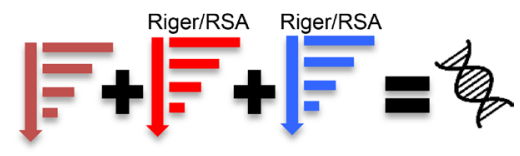

5
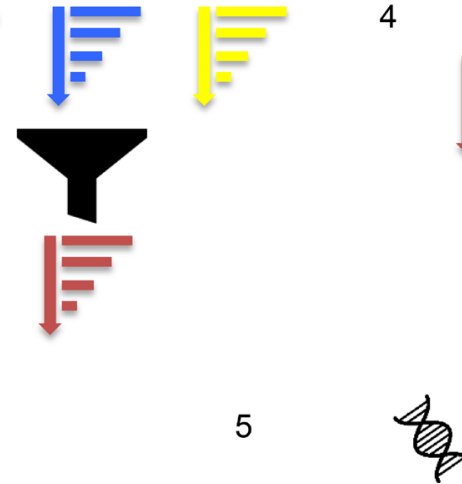

Figure 1: (1) We identified three KRAS SLP RNAi screens (Luo, Steckel, Wang) and normalized and ranked the genes per screen. (2) The three screens share 1069 genes. (3) The three rankings are aggregated by minimal displacement into one new optimized ranking (brown). (4) The ranking is combined with the established Riger and RSA ranking methods leading to a novel predicted SLP that is consistently high across screens and methods. (5) The predicted SLP is experimentally tested in a knock-down experiment. 
Spearman's footrule calculates the difference between a set of ranked lists by measuring the total number of displacements for an element (here gene) across the lists. The RankAggreg algorithm aims at minimizing Spearman's footrule between the input lists and the output aggregated list [18]. Please see Methods for more details on Spearman's footrule distance.

\section{Weighted rank aggregation on luo, wang, and steckel}

We ranked the Luo, Wang, and Steckel screens using the standard method (see Methods) and applied the above rank aggregation procedure. To reflect the screens' performance in recovering known SLP from the gold standard list we computed the fraction of gold standard genes in the top $10 \%$ and normalized the score to 1 . Using this scheme we assigned the weights $0.6,0.3$, and 0.1 to the Luo, Wang, and Steckel screens, respectively. We ran the Rank-Aggreg method 100 times, because it uses heuristics for finding the optimal ranking and therefore varies between runs.

\section{Rankings with RSA and riger}

Besides the standard method used above, RSA (Redundant siRNA Activity) and RIGER (RNAi Gene Enrichment Ranking) [19, 20] are two established and widely used ranking methods. While the standard method is applicable to all screens, RIGER and RSA require independent measurements for multiple siRNAs per gene and can therefore only be applied to Luo and Wang. RSA is considered the most robust gene ranking method in this context [17].

RIGER and RSA methods return a $p$-value for each gene, after evaluating the contribution of the different

\section{Gold Standard Gene (GSG) retrieval ratios per screen}

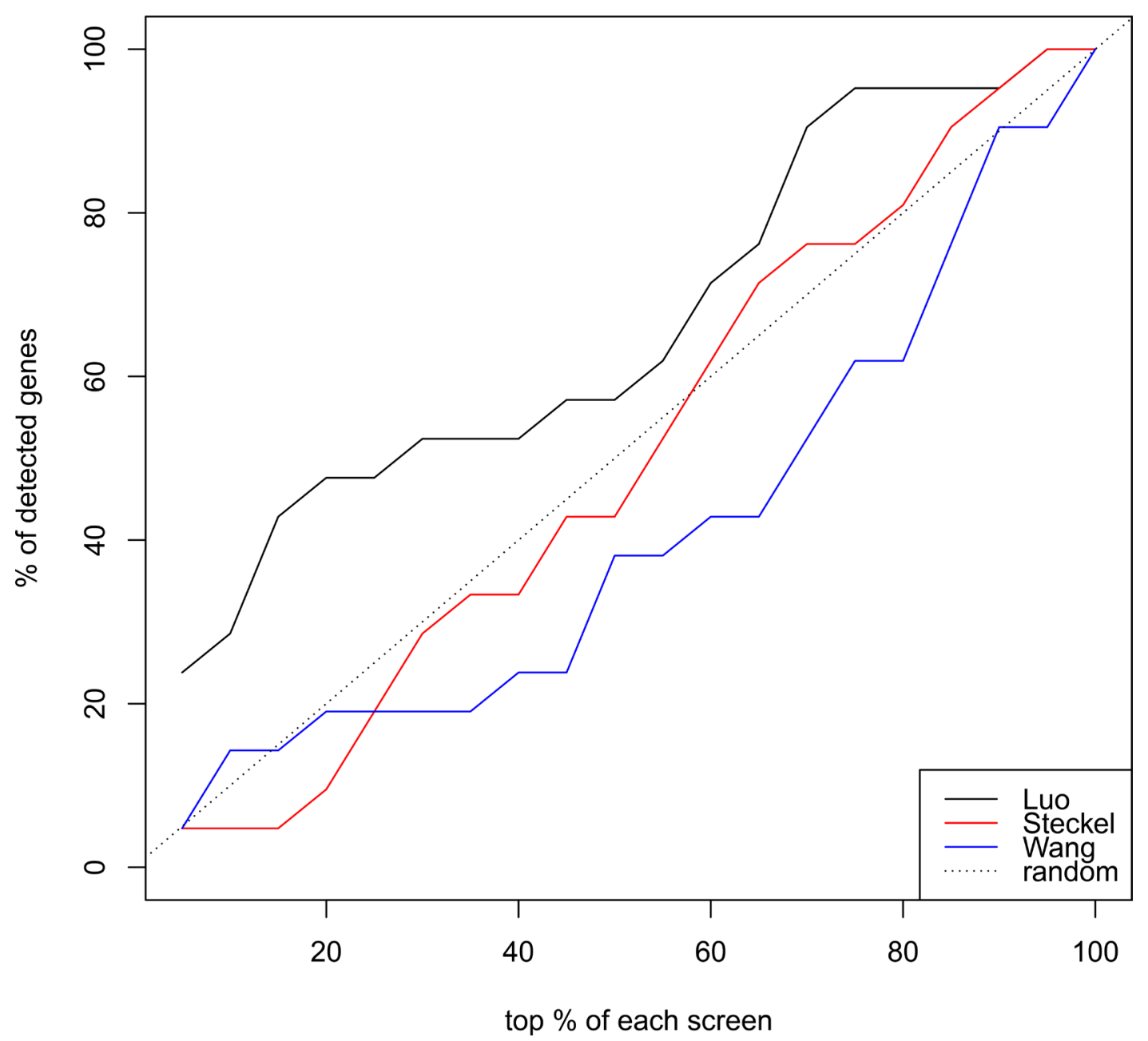

Figure 2: How well do rankings from screens recover the 21 known SLPs (gold standard), which were part of the screens? Luo (black) performs better than random, while Wang and Steckel perform slightly worst. Thus, more weight will be given to the Luo screen than to the Steckel and Wang screens. 
shRNAs that target it. The RIGER algorithm calculates a $p$-value for each gene, indicative of the significance of the differential $K R A S$ mutant and $K R A S$ wild type cell viability caused by the gene's knock down. To this aim a weighted sum approach based on the signal to noise ratio was utilized. For the RIGER method, a simple criteria of $p$-value $<0.05$ was sufficient. RSA on the other hand assigns a value to each experimental well. The inputs provided to RSA are the summarized mutant-wild type values per well for Luo and for Wang screens. According to RSA, a lower bound LB and an upper bound UB are defined, between which hit genes are sought. These bounds intuitively correspond to fold changes. Wells with lower scores than LB are guaranteed hits, whereas wells with larger scores than UB are guaranteed nonhits. After correspondence with the methods' developers and matching of the LB and UB bounds with fold change, we opted for $\mathrm{LB}=-2$ and $\mathrm{UB}=0$. There was increased confidence in favor of their being hits if the $\log$ transformed and normalized fold change is $<-2$. The ones having a positive fold change $(>0)$ correspond to the surviving cells, thus they were rejected. The most significant hits were selected based on two criteria:

The $p$-value for each gene ( $p$-values are the same for all wells corresponding to a gene) should be $<0.05$, and The gene should have at least two active wells (OP I_Rank < 99999 for at least two wells). This is interpreted as: at least two shRNAs below threshold.

It has to be noticed that the rank of at least two wells, having $p$-value $<0.05$, should be a real number (RSA returns infinite if a rank cannot be calculated).

\section{Standard ranking, RSA, and RIGER broadly agree and correlate between 60 to $80 \%$}

Rankings with the standard method and RSA and RIGER differ, but they still correlate very well. For the Luo and Wang screen, the ranks of the three methods were mapped on three axes in a 3D scatter plot (see Figure 3). The pairwise Spearman correlations range from 0.59 to 0.8. Specifically, the are for the Luo screen: StandardRIGER $=0.74$, Standard-RSA $=0.7$, RIGER-RSA $=$ 0.8 and for the Wang screen: Standard-RIGER $=0.65$, Standard-RSA $=0.59$, RIGER-RSA $=0.76$.

\section{Rank aggregation and RIGER and RSA identify COPB2 as candidate SLP}

The above analysis shows that standard method, RSA, and RIGER are not inconsistent and that there is not one method that can provide the one and only true ranking. At the same time, they are not in perfect agreement. To reflect this situation we consider the rank aggregation for all three screens as described above together with RIGER and RSA for the two screens of Luo and Wang. This is summarized as step 4 in Figure 1.
Table 2 shows the top three genes for this integrated ranking: coatomer protein complex, subunit beta 2 (COPB2), sprouty homolog 1, antagonist of FGF signaling (SPRY1), and nuclear receptor corepressor 1 (NCOR1). These three genes ranked consistently among the top $10 \%$ of all RankAggreg runs, with COPB2 ranking 98 times, NCOR1 100 and SPRY1 88 times among the top $10 \%$. Further, these genes were the only ones among the top 10\% ranks of RankAggreg that also ranked high according to RIGER and RSA. The functionalities of all three genes were explored and associated with the nine 'hallmarks of cancer' : the nine properties that are shared among cancer cells, and are necessary for tumor initiation and expansion [21]. The function of NCOR1 relates to the 'Resisting Cell Death' property. The functions of SPRY1 and COPB2 are associated with the 'Sustaining Proliferative Signaling' property. Information on the genes' function was collected from GeneCards and Pubmed (www. ncbi.nlm.nih.gov/pubmed/) and Gene Cards (www. genecards.org) [22]. Silencing of SPRY1 has been found to trigger complete regression of RAS mutant cells in the human childhood rhabdomyosarcoma (RMS) [23]. $C O P B 2$ ranked best when the cumulative rank across all methods was considered, thus we focused on COPB2 in our experimental validations.

We examined the expression levels of KRAS, COPB2, NCOR1 and SPRY1 across the five colorectal adenocarcinoma cell lines available in TCGA's cBioPortal (www.cbioportal.org) [24, 25] (Supplementary Figure 2). The expressions of COPB2 and NCOR1 have a much higher median than the KRAS expressions but wider standard deviation. This adds to our finding that they are potential $K R A S$ synthetic lethal partners; their high expressions may sustain oncogenic $K R A S$ signaling and knocking them down can have a big effect in cancer cell lines' viability. On the other hand, SPRY1 has in average lower expressions than $K R A S$.

We further examined the mutation status of KRAS and its three candidate synthetic lethal partners in published colorectal and pancreatic cancer cell lines $[24,25]$. We are expecting that $K R A S$ is very rarely mutated together with the three genes, which sustains the cell line's viability. The results shown in Table 3 prove that this hypothesis holds.

\section{Cell lines for COPB2 knock-down}

To validate the above finding, we knocked down $C O P B 2$ in the human pancreatic cancer cell lines shown in Table 4. We chose these cell lines, because they are well-known standard cells, easy to handle, suitable for transfection experiments and have different genotypes. We examined the effects of $C O P B 2$ knock down on selected protein levels to find a link between $C O P B 2$, fewer living cells, and autophagic cell death. 
Table 2: Hit gene ranks

\begin{tabular}{lllllll}
\hline \multirow{2}{*}{ Gene } & Sum & RankAggreg & \multicolumn{2}{c}{ RIGER } & \multicolumn{2}{c}{ RSA } \\
\cline { 4 - 7 } & & & Luo & Wang & Luo & Wang \\
\hline COPB2 & 300 & 18 & 223 & 5 & 43 & 1 \\
SPRY1 & 431 & 49 & 266 & 12 & 84 & 20 \\
NCOR1 & 957 & 2 & 527 & 188 & 118 & 124 \\
\hline
\end{tabular}

The ranks of COPB2, NCOR1 and SPRY1 by all methods. RIGER and RSA can only be calculated for the Luo and Wang screens. In this case, the ranks range from 1 to 1423 , which is the number of common genes between Luo and Wang screens. RankAggreg ranks range from 1 to 1069.

Table 3: Co-occurring mutations of the hit genes across publicly available pancreatic and colorectal cancer cell lines

\begin{tabular}{|c|c|c|c|c|c|}
\hline Study & Samples & $\% K R A S$ & $\%$ COPB2 & $\%$ NCOR1 & $\%$ SPRY1 \\
\hline DFCI, Cell Reports 2016 [26] & 619 & $28 \%$ & $2.3 \%$ & $2.9 \%$ & $0.5 \%$ \\
\hline Genentech, Nature 2012 [27] & 72 & $51 \%$ & $4 \%$ & $4 \%$ & $1.4 \%$ \\
\hline MSKCC, Genome Biol 2014 [28] & 138 & $55 \%$ & 0 & 0 & 0 \\
\hline TCGA, Nature 2012 [29] & 276 & $42 \%$ & $2.20 \%$ & $4 \%$ & $1.3 \%$ \\
\hline $\begin{array}{l}\text { Colorectal Adenocarcinoma, TCGA } \\
\text { Provisional [30] }\end{array}$ & 633 & $43 \%$ & $2.2 \%$ & $4 \%$ & $1.3 \%$ \\
\hline ICGC, Nature 2012 [31] UTSW, & 99 & $95 \%$ & 0 & 0 & 0 \\
\hline Nat Commun 2015 [32] QCMG, & 109 & $93 \%$ & $2.8 \%$ & $6 \%$ & $6 \%$ \\
\hline Nature 2016 [33] UTSW, & 383 & $90 \%$ & $0.3 \%$ & $0.5 \%$ & 0 \\
\hline Nat Commun 2015 [32] Pancreatic & 109 & $93 \%$ & $2.8 \%$ & $6 \%$ & $6 \%$ \\
\hline Adenocarcinoma, TCGA Provisional [30] & 149 & $91 \%$ & $0.7 \%$ & $2.7 \%$ & 0 \\
\hline
\end{tabular}

Western Blot analysis (see Figures $4,5,6$ ) revealed effects of COPB2 knock-down on the cellular level of proteins involved in KRAS signaling, apoptosis and autophagy in all pancreatic tested cell lines. These figures are duplicated from the original for presentation and explanation purposes. The original western blot is provided in Supplementary Figure 1.

\section{COPB2 knock down and signalling}

We first examined the phosphorylation of downstream effectors of KRAS, Protein kinase B (Akt) and extracellular-signal-regulated kinases ERK1/2, in order to see if the downstream KRAS pathway was silenced. Indeed, the phosphorylation levels of the selected proteins were lower after COPB2 knock-down only in MIAPaCa2 and Hs766T cells (homozygous KRAS mutant).

\section{$C O P B 2$ knock down and apoptosis}

We then examined how cell apoptosis is affected by $C O P B 2$ knock down. A good indicator for apoptosis induction is Poly (ADP-Ribose) Polymerase (PARP) cleavage. Enhanced levels of cleaved PARP were detected after $C O P B 2$ knockdown in all cell lines compared to their negative control, except KRAS wild type BxPC3. Therefore, apoptosis, which could contribute to the reduction of living cells, was induced in those cell lines. Anti-apoptotic proteins like cFLIP, XIAP and BCL-XL showed a decreased expression after $C O P B 2$ knock-down in Hs766T cells. Importantly, Signal Transducer and Activator of Transcription 3 (STAT3), a key transcription factor of cell growth and apoptosis, showed a reduction of its phosphorylated form in cell lines MIAPaCa2, Hs766T and $\mathrm{PaCaDD} 165$, meaning that downstream pro-survival functions might be inhibited.

\section{COPB2 knock down and autophagy}

Finally, conversion of Microtubule-associated protein light chain 3 I (LC3) to LC3 II is a marker of autophagy with the amount of LC3 II negatively correlating to the number of autophagosomes. In our comparison of the negative control to the $C O P B 2$ knockdown there was a clear increase of LC3II level in Hs766T, $\mathrm{PaCaDD} 165$, Panc1 and MIAPaCa2, thereby exhibiting an increase in autophagy after COPB2 knock-down. 
Luo: 3D Scatterplot

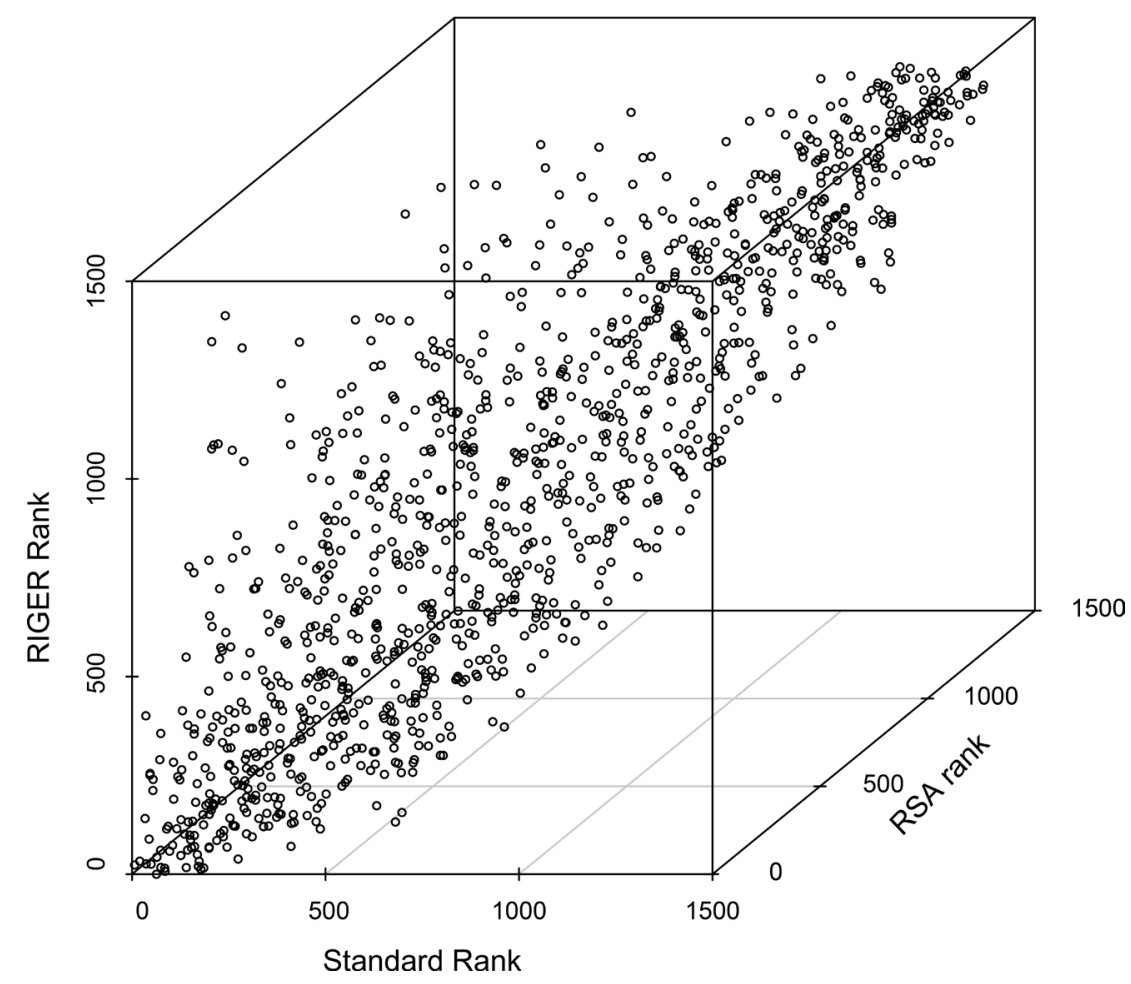

Wang: 3D Scatterplot

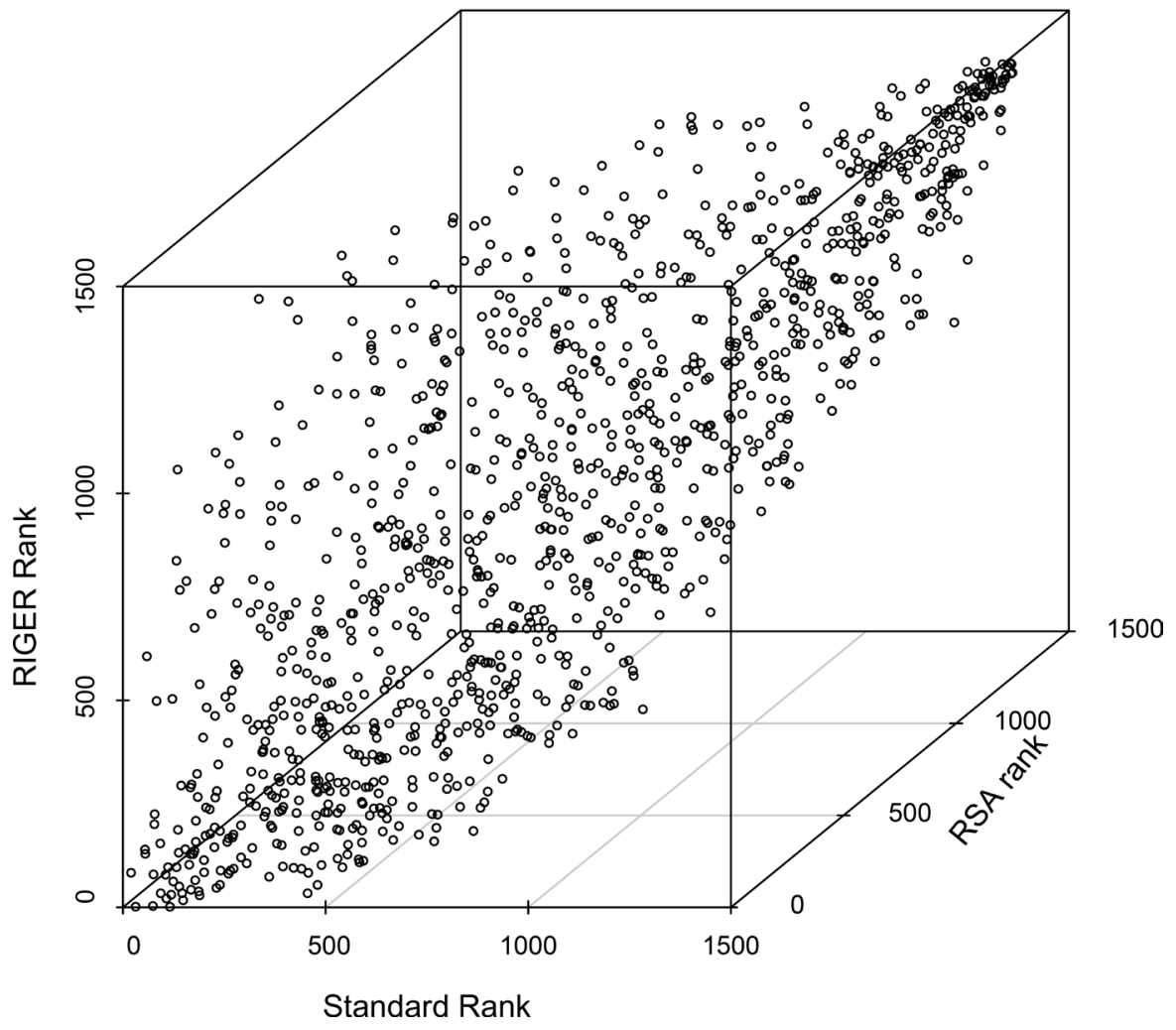

Figure 3: Comparison of standard ( $\mathrm{x}$-axis), RSA (y-axis), and RIGER (z-axis) ranking for the Luo (left) and Wang (right) screens. Rankings differ, but agree broadly with correlation coefficients from 0.59 to 0.8 . 
Table 4: Experimental cell lines

\begin{tabular}{|c|c|}
\hline Cell line & $K R A S$ status \\
\hline MIAPaCa2 & $K R A S^{\mathrm{G} 12 \mathrm{C} / \mathrm{G} 12 \mathrm{C}}$ mutant \\
\hline Hs766T & $K R A S^{\mathrm{Q} 61 \mathrm{H} / \mathrm{Q} 61 \mathrm{H}}$ mutant \\
\hline Panc1 & $K R A S^{+/ G 12 \mathrm{D}}$ mutant \\
\hline BxPC3 & $K R A S^{+/+}$wild type \\
\hline PaCaDD165 & $K R A S^{+/+}$wild type \\
\hline DLD-1 & $K R A S^{+/ \mathrm{G} 13 \mathrm{D}}$ mutant \\
\hline
\end{tabular}

\section{$C O P B 2$ knock down and living cell counts}

More importantly, the change in expression levels of relevant genes is complemented by changes in living cell counts (see Figures 7 and 8) Homozygous pancreatic KRAS mutated cell lines MIAPaCa2 and Hs766T, show a high reduction of living cells after COPB2 knock down onto $16.93 \%( \pm 4.34 \%)$ and $24.22 \%( \pm 2.19 \%)$ compared to the negative control (nc). The number of living cells in the KRAS wild type cell lines $\mathrm{BxPC} 3$ and PaCaDD 165 , was reduced to $63.74 \%( \pm 7.64 \%)$ and $65.44 \%( \pm$ $5.53 \%)$. Heterozygous $K R A S$ mutated cell line Panc1 also had a cell count of $68.81 \%( \pm 4.62 \%)$. These results show that there is a significant difference regarding the reduction of living cells after $C O P B 2$ knock down in homozygous KRAS mutated cell lines, MIAPaCa2 and Hs766T, compared to the KRAS wildtype cell lines, BxPC3 and PaCaDD165, and KRAS heterozygous mutated Panc1.

In addition, there is a significant difference regarding the reduction of living cells after $C O P B 2$ knock down in the heterozygous colorectal cancer cell line DLD-1, compared to negative control (Figure 8).

The above results confirm our speculation about a correlation between KRAS mutation status and COPB2 sensitivity on the selected pancreatic and colorectal carcinoma cell lines.

Single inhibition of $K R A S$ or simultaneous inhibition of both KRAS and COPB2, to further support our finding, has not been conducted. However, we recently performed a similar experiment where we inhibited KRAS and the anti-apoptotic genes $B C L X L$, FLIP, MCLIL, SURVIVIN and XIAP in a panel of murine and human pancreatic cancer cell lines, including the ones that we employed in the current work. Single inhibition of $K R A S$ had little effect in cell apoptosis. Simultaneous inhibition of $K R A S$ and the anti-apoptotic proteins significantly induced apoptosis and inhibited proliferation of the cell. This finding was validated in vivo on mice. Given the role of $C O P B 2$ in apoptosis signaling, as shown by our experiments (see Figure 5), we suspect that the simultaneous inhibition of $C O P B 2$ and $K R A S$ in pancreatic cancer cells will be more effective than $C O P B 2$ silencing alone.

\section{DISCUSSION}

In this work, we analyzed three different RNAi screens that are designed to detect KRAS synthetic lethal partners and combined them using a computational framework. Our methodology detected COPB2 as the most promising KRAS synthetic lethal partner, which was further experimentally evaluated.

Our experimental data, comparing pancreatic and colorectal cancer cell lines with different $K R A S$ genotypes after $C O P B 2$ knock down, implicate that this knock down has a higher negative impact on the number of living cells in the case of homozygous pancreatic KRAS mutated cells and heterozygous colorectal cells, with respect to the $K R A S$ wild type cells (Figures 7 and 8).

Knock down approaches and western blot analysis in pancreatic cell lines demonstrated that COPB2 influences KRAS signaling, apoptosis and autophagy (see Figures 4, 5, and 6). Pancreatic tumor cells depend on KRAS signaling, on evasion of apoptosis and on autophagy to sustain themselves and proliferate [34], [21], [35]. Thus, when the above are impaired, pancreatic tumor cells are put under stress and are more susceptible to death. Regarding autophagy, we noticed an increase in LC3 protein after $C O P B 2$ knock down (Figure 6), which is interpreted as a decrease in autophagy [36]. In the past, it has been shown that COPB2 (COPI subunit) knock down disables autophagy [37], which in turn leads to abortive autophagy [38]. With respect to pancreatic cancer, it is known that pancreatic tumor growth relies on autophagy [35], especially in $K R A S$ mutated cells where metabolism is deprogrammed. Thus when autophagy is decreased, tumor growth is inhibited. Further investigations could involve measurement of the exact amount of apoptotic cells, the cause of cell death, qPCR to determine the effects on mRNA level, migration assays and proliferation assays.

Knock down approaches and western blot analysis in colorectal cell line DLD-1 demonstrated that COPB2 was efficiently knocked-down whereas $K R A S$ remained intact. This knock-down resulted in significantly reduced number of colorectal cancer living cells (Figure 8). Although we have not tested the levels of LC3 protein after COPB2 knock-down in DLD-1 cells, we suspect that autophagy is one of their survival mechanisms too, based on existing literature [39, 40]. 


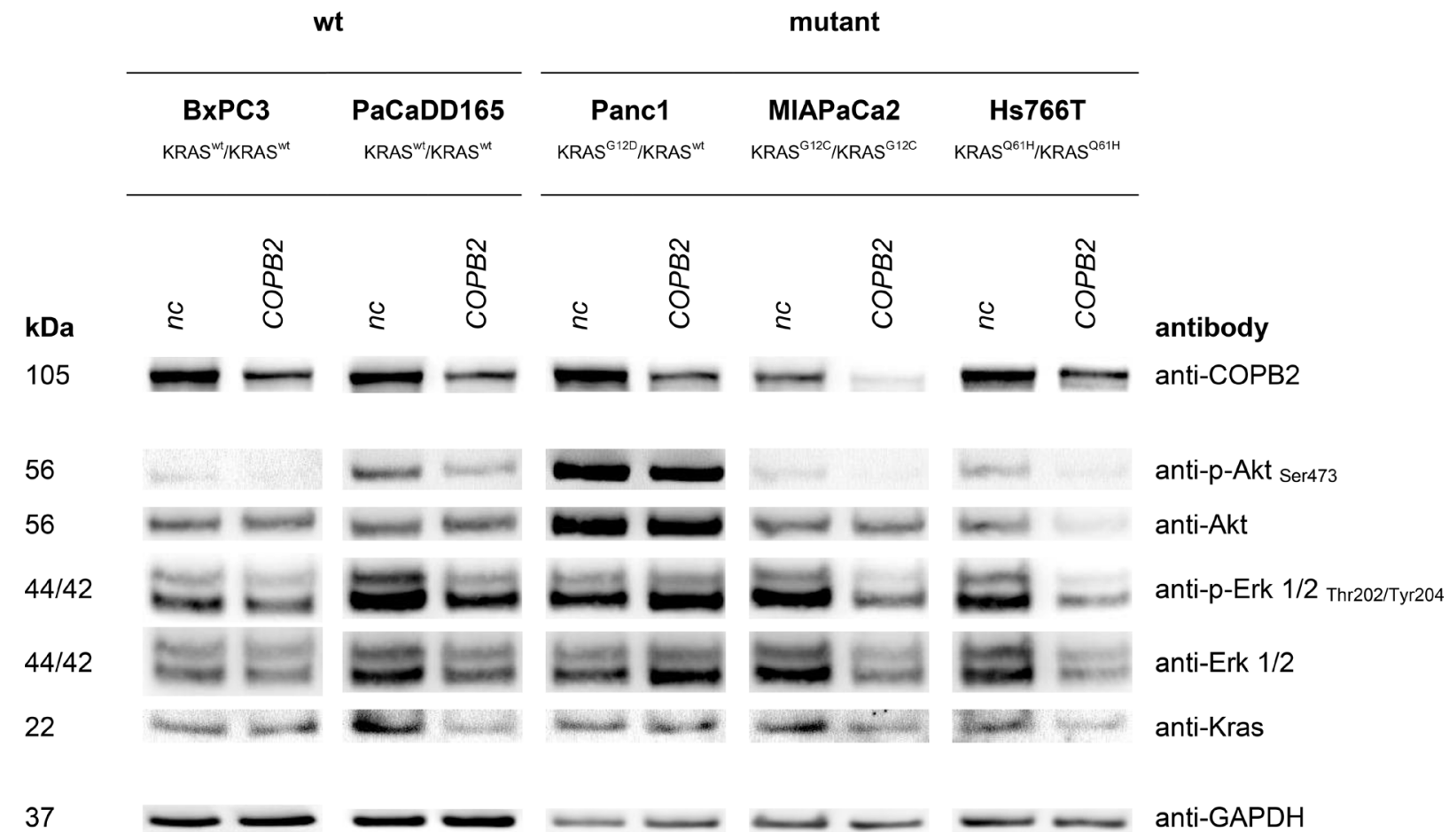

Figure 4: KRAS signaling: Top western blot row shows that $C O P B 2$ is effectively knocked down in all cell lines. The rest rows show the effects of COPB2 knock down on downstream KRAS signaling. GAPDH is used as control.

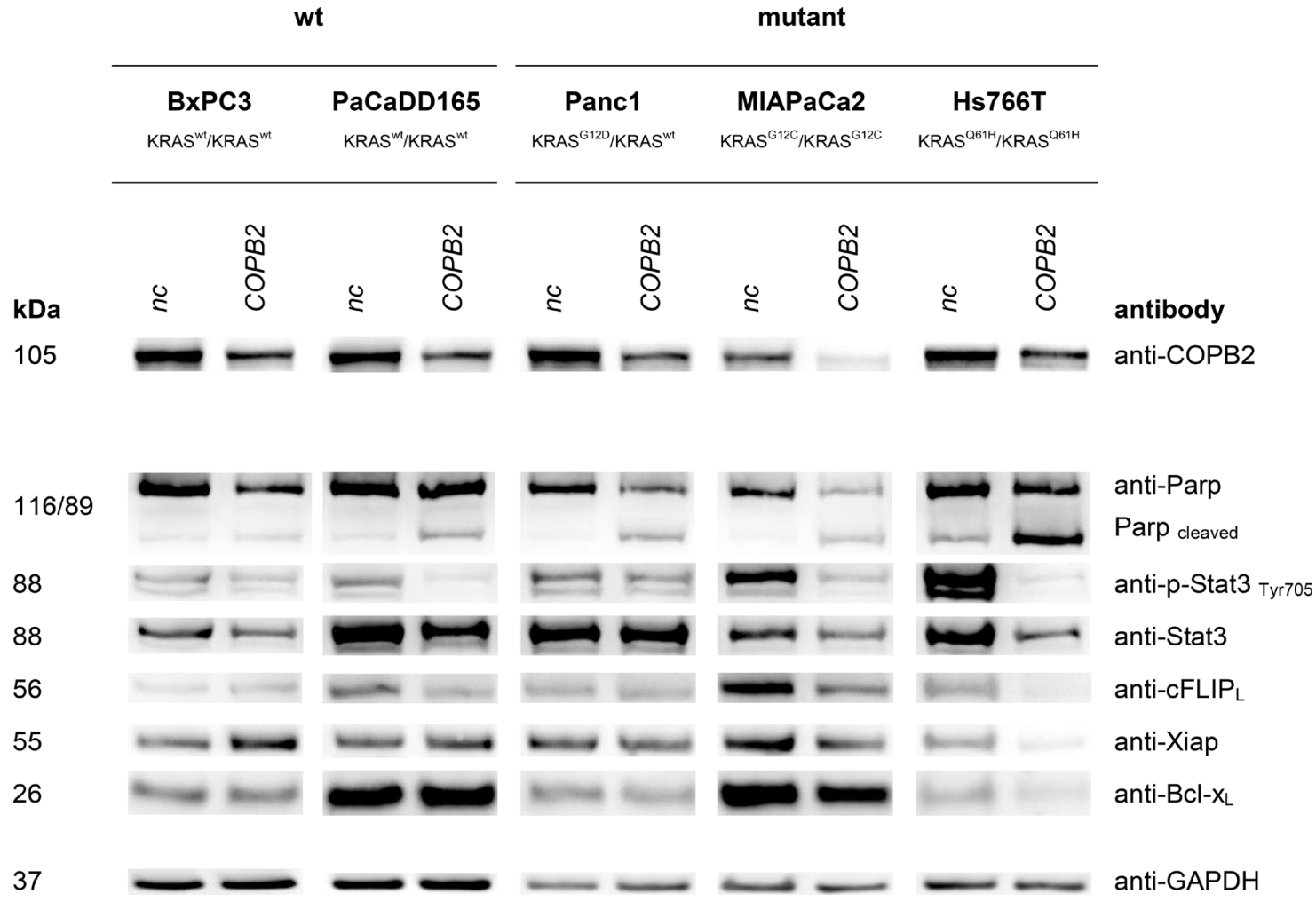

Figure 5: Apoptosis: Top western blot row shows that $C O P B 2$ is effectively knocked down in all cell lines. The rest show the effects of $C O P B 2$ knock down on apoptosis signaling. GAPDH is used as control. 
Expression of COPB2 maybe linked to KRAS signaling as follows: Activated KRAS activates downstream RalGDS signaling [41]. As a consequence, the small GTPases RALA and RALB are activated. They play a major role in vesicular trafficking and tumor proliferation [42]. It is noticeable that $R A L B$ also promotes autophagy. In mammals, the coatomer subunit, which contains $C O P B 2$, can only be recruited when activated small guanine triphosphatases (GTPases) attract coat proteins to specific membrane export sites, thereby

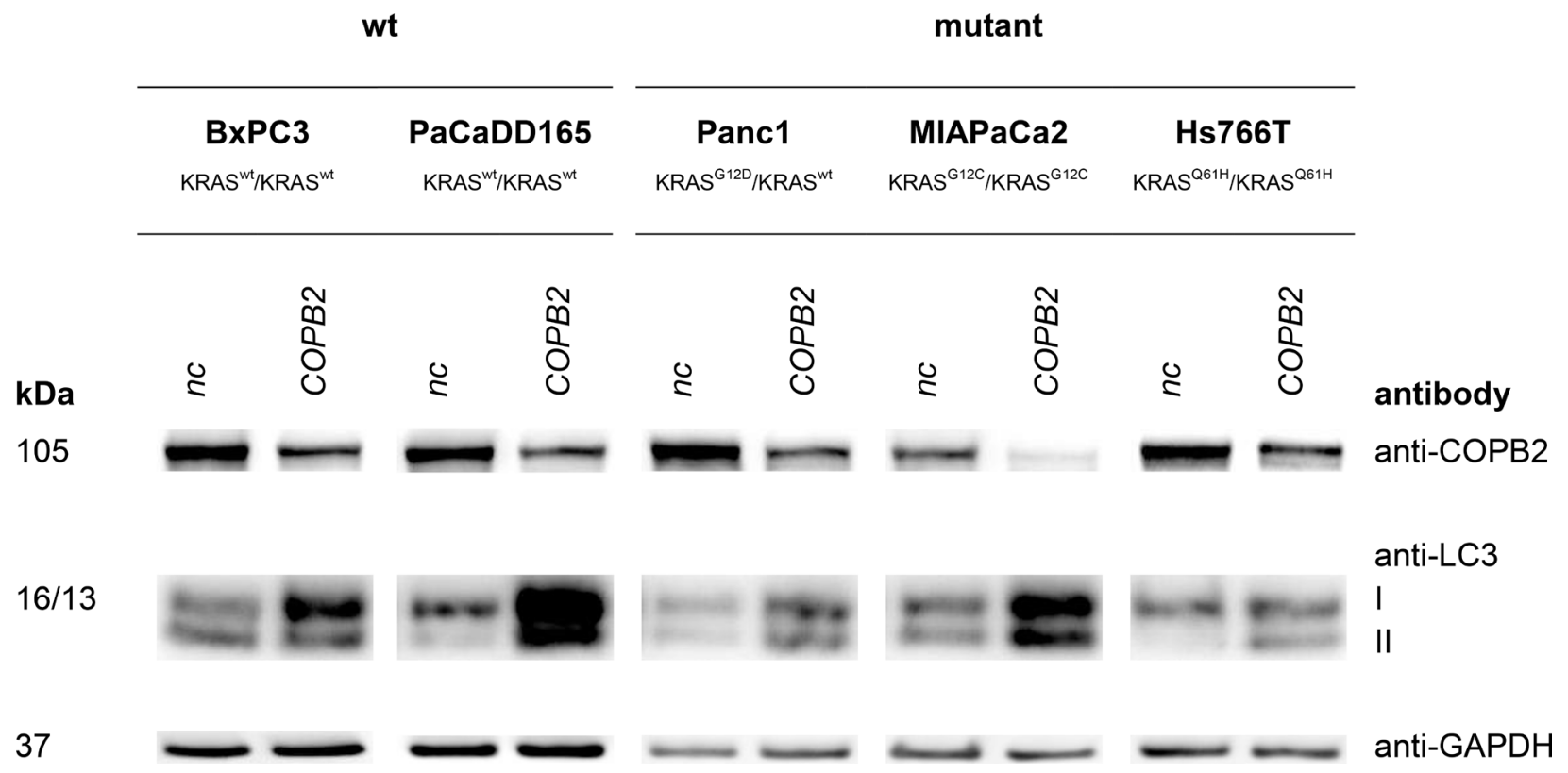

Figure 6: Autophagy induction: Top western blot row shows that $C O P B 2$ is effectively knocked down in all cell lines. The rest show the effects of $C O P B 2$ knock down on down on autophagy-related proteins. GAPDH is used as control.
$\square \mathrm{BxPC3}(\mathrm{wt})$
Q PaCaDD165 (wt)
$\square$ PANC-1 (G12D hetero)
$\triangle \mathrm{MIAPaCa} 2(\mathrm{G} 12 \mathrm{C})$
$\square \mathrm{Hs766T}(\mathrm{Q} 61 \mathrm{H})$

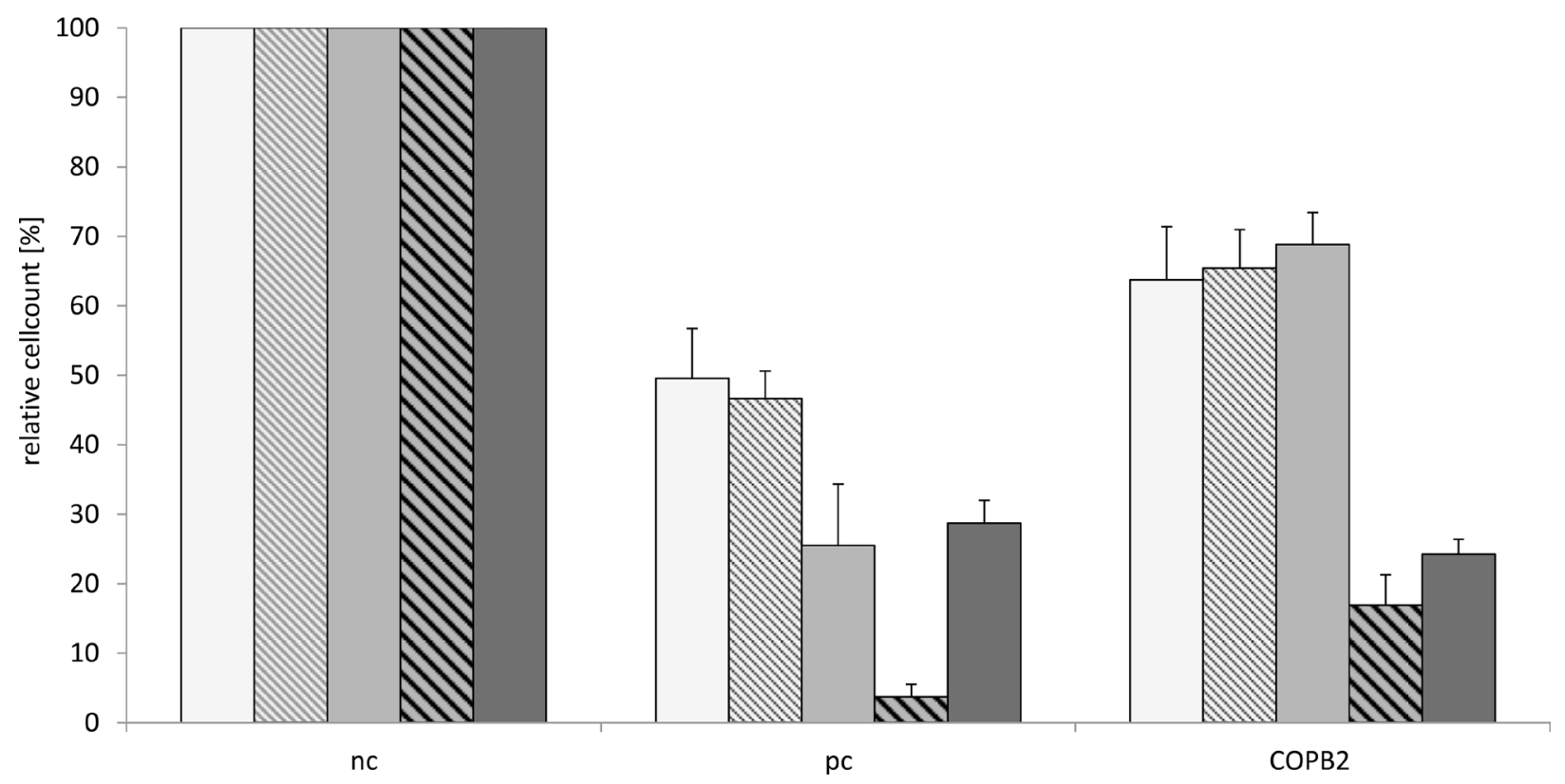

Figure 7: $C O P B 2$ knock down reduces number of living cells in pancreatic cancer cell lines depending on their $K R A S$ genotype. Each cell line's KRAS genotype is shown in Table 4 . After $72 \mathrm{~h}$ of transfection using $72 \mathrm{nM}$ non-coding siRNA (negative control, nc), KIF11 siRNA (positive control, pc) and COPB2 siRNA (COPB2) cell number was quantified in KRAS wildtype (wt) and mutated pancreatic cancer cell lines. The $p$-value is $p<0.01$ in cell line specific comparison. 
linking coatomers to export cargos [43]. We believe that the involvement of $R A L A$ and $R A L B$ in vesicular trafficking, in which COPB2 is also involved, and the colocalization of KRAS transcripts in the Golgi complex [44] may support the positive feedback loop: GTP $K R A S \rightarrow$ $C O P B 2 \rightarrow$ GTP $K R A S$.

We note here that, according to Ihle et al., the Ral-GDS pathway is enabled only when the activated $K R A S^{\mathrm{G} 12 \mathrm{C}}$ binds to it [45]. $K R A S^{\mathrm{G} 12 \mathrm{D}}$, on the other hand, activates PI3K signaling. In our experiment, Panc1 heterozygous mutant $K R A S^{\mathrm{G} 12 \mathrm{D}}$ cell line exhibits similar behavior with wild type $K R A S$ pancreatic tumor cells. We believe that in this case the PI3K pathway is activated instead of the Ral-GDS. In contrast, COPB2 knock-down significantly decreases the viability of the homozygous $K R A S^{\mathrm{G} 12 \mathrm{C}}$ MIAPaCa2 cell line, probably due to the activation of Ral-GDS. Another possible reason for the behavior of Panc1, is that Panc1 has high latency period before tumor progression, comparable to that of the wild type $\mathrm{BxPC} 3$ cell line [46]. So maybe the behavior of Panc1 after $72 \mathrm{~h}$ of treatment, which we examined, is closer to wild type cells. In regards to why this happens, it seems that the fate of a cell that contains both oncogenic and wild type $K R A S$, depends on the type of the wild type allele ( $R A S-\mathrm{GDP}$ or $R A S$-GTP) and on the status of other tumor suppressor and cell cycle inhibitor genes [47].

The current findings agree with past studies, as there is supportive evidence from literature that $C O P B 2$ knock down undermines survival of $K R A S$ mutant cells, meaning that survival of cells is decreased by the knock down; experiments on non small cell lung cancer (NSCLC) cells show that there is a COPI addiction in KRAS and $L K B 1$ mutated cell lines [48].
As a last note, we used RNAi knock-down technology to silence the gene of interest because the original screens, from which we derive our hypotheses, use RNAi. For the sake of comparability we decided for RNAi and not CRISPR/Cas9 which is another promising gene-editing technology. Unniyampurath et al. explain that RNAi and CRISPR/Cas9 are two different technologies, of which the outcome does not necessarily overlap [49]. This mainly happens because CRISPRs regulate gene transcription by altering the DNA (pre-transcription level) whereas RNAi regulates gene transcription by acting posttranscriptionally. siRNA and shRNA approaches are excellent as the first attempt to understand the function of the gene of interest. CRISPR/Cas9 system is the next logical step to fully elucidate the function of the gene and to validate phenotypes observed by knock-down approaches.

This study has shown that consistent data integration identified a novel synthetic lethal partner of $K R A S$, which could be experimentally confirmed in our knock-down experiments. However, future work has to be done to validate our finding in vivo and in vitro, with additional knock-down experiments with other RNAi constructs and more cell lines.

\section{MATERIALS AND METHODS}

\section{Standard RNAi screen ranking method}

Luo and Wang screens contain three replicate measurements for each cell line. Having only three replicates per cell line, normal distribution was safely assumed. All the shRNAs targeting a gene were included

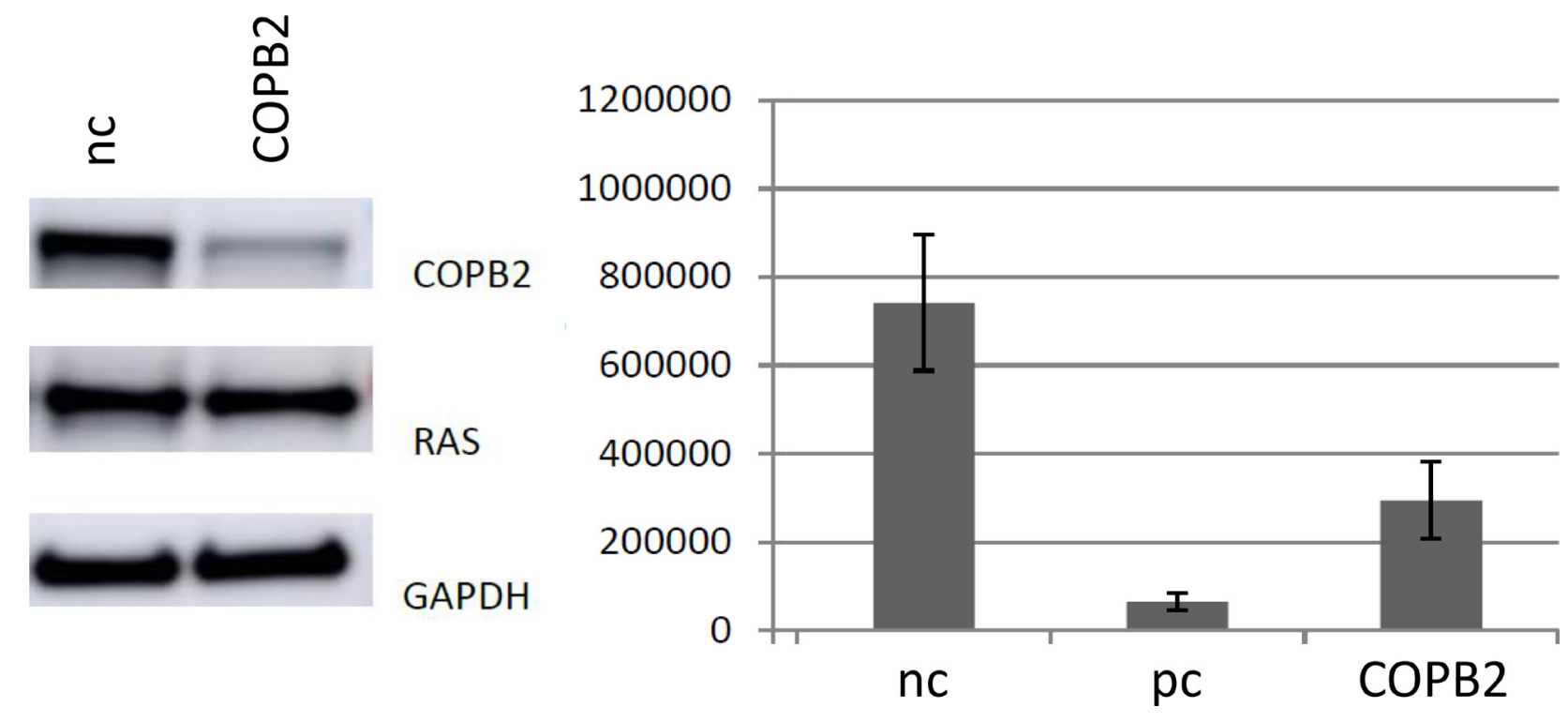

Figure 8: Left Knockdown of COPB2 in DLD-1 cells, indicating a knock-down of COPB2, but no significant loss of $\boldsymbol{K} \boldsymbol{R} \boldsymbol{A S}$ expression in this cell line. Right Knockdown of COPB2 in DLD-1 cells leads to a reduction in cell number after $72 \mathrm{~h}$ of transfection $(p<0.01)$. nc stands for negative control, pc stands for positive controltion of the gene of interest. 
and ranked based on their differential effect on the viability of the KRAS mutant versus $K R A S$ wild type cells. This was captured by the paired $t$-test. The null hypothesis tested was that depletion of a specific shRNA has no significant effect on the viability between $K R A S$ mutant and $K R A S$ wild type cell lines. The respective alternative hypothesis was that the viability of the $K R A S$ mutant cells decreases more than the viability of their isogenic wild type counterparts. A gene was reported as hit when the best-ranking of all the shRNAs that target it was below threshold. Our assumption at this point is that if one shRNA depletes the target gene, then the observed phenotype is cell death. Regarding the Steckel screen, no replicate data were provided. Thus, only the difference of the z-scores (mutant-wild type) was considered. This is an apoptosis screen, so the result has been inverted in order to be comparable to the other two viability screens. The rank $r$ in this case was calculated as:

$$
\mathrm{r}=-\operatorname{rank}\left(\text { z.score }_{\text {mut }}-\text { z.score }_{\mathrm{wt}}\right)
$$

The $p$-value threshold for the Standard method and for the Luo and Wang screens was set to 0.05 . The z-score threshold for the standard method and for the Steckel screen was set to -1 .

\section{Rank aggregation}

We aggregated the common gene rankings from the individual screens to a global ranking, which best reflects the ordering of the input lists. Rank aggregation is an optimization problem and one possible way to generate the final list is by using heuristic functions. To this aim, the RankAggreg R method was used, which supports the Genetic Algorithm (GA) and Cross Entropy Monte Carlo (CE) heuristics [18].

Both heuristics are iterative. The methods converge when the optimal super-list remains optimal for a number of consecutive iterations, based on the distance between each iteration's output list with each of the input lists. This distance has to be as small as possible. Spearman's footrule distance was chosen because it can quickly be computed in linear time and is a non-trivial 2-approximation of Kemeny's local optimization, as proven by the DiakonisGraham inequality: For any two full lists $\sigma, \tau: \mathrm{K}(\sigma, \tau)$ $\leq \mathrm{F}(\sigma, \tau) \leq 2 \mathrm{~K}(\sigma, \tau)$, where $\mathrm{K}$ is the Kemeny local optimization and $\mathrm{F}$ the Spearman footrule distance [50].

\section{Spearman's footrule distance}

We want to compare an aggregated ranking $r$ against $m$ rankings $r_{1, \ldots,} r_{m}$. All of the rankings range from 1 to $n$. We use Spearman's footrule to compare the displacement between $r$ and $r_{k}$ and then we sum up these displacements for all $\mathrm{m}$ rankings. Formally, the displacement $\mathrm{D}$ between $r$ and $r_{k}$ is defined as

$$
\mathrm{D}_{\mathrm{r}}\left(\sigma_{\mathrm{k}}\right)=\sum_{\mathrm{i}=1}^{\mathrm{n}}\left|\sigma_{\mathrm{k}}(\mathrm{i})-\mathrm{i}\right| \text {. }
$$

where $\sigma_{k}$ is a permutation of $n$ elements, such that the element at position $\mathrm{i}$ in the ranking $\mathrm{r}$ is at position $\sigma_{\mathrm{k}}$ (i) in the ranking $r_{k}$. I.e. Spearman's footrule sums up the differences in position in $r$ and $r_{k}$ for all elements $i$. Note, if the rankings $r$ and rk are identical, then $\mathrm{D}_{\mathrm{r}}\left(\sigma_{\mathrm{k}}\right)=0$.

To evaluate the distance of a ranking $\mathrm{r}$ to $\mathrm{r} 1, \ldots$, rm we simply sum up:

$$
\mathrm{D}_{\mathrm{r}}=\sum_{\mathrm{k}=1}^{\mathrm{m}} \mathrm{D}_{\mathrm{r}}\left(\sigma_{\mathrm{k}}\right)
$$

Now we can optimize. For rank aggregation we search for a ranking $r$, that minimizes $D_{r}$. This minimization step is implemented in the RankAggreg algorithm [18].

\section{COPB2 knock down}

\section{Cell culture}

The human pancreatic cancer cell lines DLD-1, BxPC3, MIAPaCa2 and Panc1 were obtained from the American Type Culture Collection. Hs766T was kindly provided by Tatjana Crnogorac-Jurcevic (Centre for Molecular Oncology, Barts Cancer Institute, UK). The primary cell line PaCaDD165 was established following the Dresden Outgrowth protocol [51].

DLD-1, BxPC3 and Panc1 cells were cultivated in RPMI-1640 supplemented with $10 \%$ fetal calf serum (FCS), MIAPaCa 2 cells in DMEM with $10 \% \mathrm{FCS}$ and $2.5 \%$ horse serum and Hs766T in DMEM with $10 \%$ FCS. Primary cells were cultured in DMEM with 20\% FCS and 50\% K-SFM. All cell lines were maintained in a humidified $5 \% \mathrm{C} \mathrm{O} 2$ incubator at $37^{\circ} \mathrm{C}$.

\section{Transfection}

For each transfection, $72 \mathrm{nM}$ siRNA were transfected using OligofectamineTM Transfection Reagent (Invitrogen) according to the manufacturer's protocol. Transfected cells were analyzed after $72 \mathrm{~h}$. SiRNA against COPB2 was acquired from QIAGEN (FlexiTube siRNA Cat. No. 1027415) with the following target sequence: CAGGTTTCAAGGGTAGTGAAA. Noncoding siRNA Allstars provided by QIAGEN was used as a negative control. SiRNA against essential cytoskeletal motor protein coding gene KIF11 with the sequence AACUGAAGACCUGAAGACAAU served as a positive control. Gene silencing was confirmed by Western Blot analysis.

\section{Western blot analysis}

Transfected cells were washed and homogenized in a protein lysis buffer (RIPA buffer). Protein concentrations were quantified using BCA Protein Assay Kit (Pierce). $10 \mu \mathrm{g}$ of each sample were denaturized at $95^{\circ} \mathrm{C}$ for $10 \mathrm{~min}$ and further processed using the NuPAGE SDSPAGE Gel System (Invitrogen). Proteins were 
transferred electrophoretically to a nitrocellulose membrane (Hybond ECL, GE Healthcare), which was treated afterwards with 5\% skimmed milk powder in TBS Tween $0.1 \%$. Primary antibodies were applied to the membrane according to manufactures' protocol: anti-pAKT Ser473 (Cell Signaling), anti-AKT (Cell Signaling), anti-BCL-X S/L (Santa Cruz Biotechnology), anti-cFLIP S/L (Adipogen) anti-COPB2 (novus Biologicals), anti-pERK1/2 Thr202/Tyr204 (Cell Signaling), anti-ERK1/2 (Cell Signaling), anti-GAPDH (Cell Signaling), antiKRAS (Santa Cruz Biotechnology), anti-LC3 (Cell Signaling), anti-pSTAT3 (Tyr705) (Cell Signaling), antiSTAT3 (Cell Signaling), anti-PARP (Cell Signaling), antiXIAP (BD Biosciences). The membrane was washed and incubated with the appropriate horseradish peroxidaseconjugated antiMouse or anti-Rabbit secondary antibodies (Cell Signaling). The chemiluminiscent reaction was initialized using Immobilon Western Chemiluminescent HRP Substrate (Millipore) and detected by G:Box Chemi XT4 (Syngene) (Figures 4, 5, 6).

\section{Quantification of living cells}

A reduction of living cells can refer to proliferation inhibition as well as apoptosis induction. Transfected cells were trypsinized following standard cell culture practices and counted by TC-20 Automated Cell Counter (BIORAD). Count of COPB2 siRNA treated cells (COPB2) were normalized to its noncoding siRNA control (nc).

\section{CONCLUSIONS}

In this work we aim at the detection of reliable and robust KRAS Synthetic Lethal Partners, though combination of exiting datasets. In summary, we have shown that a meta analysis consistently integrating large scale RNAi data is able to generate new hypotheses, which were not prominent in the individual screens. Here, we identified $C O P B 2$ as such candidate that was screened three times and missed three times. However, in the meta analysis, $C O P B 2$ ranks top and experimental validation confirms its role as synthetic lethal partner for $K R A S$. Evidence from literature and COPB2's role in autophagy and apoptosis further support the experimental finding.

\section{ACKNOWLEDGMENTS AND FUNDING}

We would like to thank Ji Luo, David Hancock, Julian Downward for fruitful discussion on their screens, Jaiswal Alok for providing information on the Wang screen, as well as Joshua Gould, Yingyao Zhou for feedback on RIGER and RSA methods. Eleni G. Christodoulou thanks Stylianos Makrogkikas for critical reading.

\section{CONFLICTS OF INTEREST}

None.

\section{REFERENCES}

1. Bos JL. ras oncogenes in human cancer: a review. Cancer Res. 1989; 49:4682-89.

2. Young A, Lyons J, Miller AL, Phan VT, Alarcón IR, McCormick F. Ras signaling and therapies. Adv Cancer Res. 2009; 102:1-17. doi: 10.1016/S0065-230X(09)02001-6.

3. Downward J. Targeting RAS signalling pathways in cancer therapy. Nat Rev Cancer. 2003; 3:11-22. doi: 10.1038/ nrc969.

4. Ostrem JM, Peters U, Sos ML, Wells JA, Shokat KM. K-Ras(G12C) inhibitors allosterically control GTP affinity and effector interactions. Nature. 2013; 503:548-51. doi: 10.1038/nature12796.

5. Reinhardt HC, Jiang H, Hemann MT, Yaffe MB. Exploiting synthetic lethal interactions for targeted cancer therapy. Cell Cycle. 2009; 8:3112-19. doi: 10.4161/cc.8.19.9626.

6. Beyer A, Bandyopadhyay S, Ideker T. Integrating physical and genetic maps: from genomes to interaction networks. Nat Rev Genet. 2007; 8:699-710. doi: 10.1038/nrg2144.

7. Gelmon KA, Tischkowitz M, Mackay H, Swenerton K, Robidoux A, Tonkin K, Hirte H, Huntsman D, Clemons M, Gilks B, Yerushalmi R, Macpherson E, Carmichael J, et al. Olaparib in patients with recurrent high-grade serous or poorly differentiated ovarian carcinoma or triple-negative breast cancer: a phase 2, multicentre, open-label, nonrandomised study. Lancet Oncol. 2011; 12:852-61. doi: 10.1016/S1470-2045(11)70214-5.

8. Dietlein F, Kalb B, Jokic M, Noll EM, Strong A, Tharun L, Ozretić L, Künstlinger H, Kambartel K, Randerath WJ, Jüngst C, Schmitt A, Torgovnick A, et al. A Synergistic Interaction between Chk1- and MK2 Inhibitors in KRASMutant Cancer. Cell. 2015; 162:146-59. doi: 10.1016/j. cell.2015.05.053.

9. Barbie DA, Tamayo P, Boehm JS, Kim SY, Moody SE, Dunn IF, Schinzel AC, Sandy P, Meylan E, Scholl C, Fröhling S, Chan EM, Sos ML, et al. Systematic RNA interference reveals that oncogenic KRAS-driven cancers require TBK1. Nature. 2009; 462:108-12. doi: 10.1038/ nature 08460.

10. Luo J, Emanuele MJ, Li D, Creighton CJ, Schlabach MR, Westbrook TF, Wong KK, Elledge SJ. A genome-wide RNAi screen identifies multiple synthetic lethal interactions with the Ras oncogene. Cell. 2009; 137:835-48. doi: 10.1016/j.cell.2009.05.006.

11. Steckel M, Molina-Arcas M, Weigelt B, Marani M, Warne PH, Kuznetsov H, Kelly G, Saunders B, Howell M, 
Downward J, Hancock DC. Determination of synthetic lethal interactions in KRAS oncogene-dependent cancer cells reveals novel therapeutic targeting strategies. Cell Res. 2012; 22:1227-45. doi: 10.1038/cr.2012.82.

12. Wang Y, Ngo VN, Marani M, Yang Y, Wright G, Staudt LM, Downward J. Critical role for transcriptional repressor Snail2 in transformation by oncogenic RAS in colorectal carcinoma cells. Oncogene. 2010; 29:4658-70. doi: 10.1038/onc.2010.218.

13. Singh A, Greninger P, Rhodes D, Koopman L, Violette S, Bardeesy N, Settleman J. A gene expression signature associated with "K-Ras addiction" reveals regulators of EMT and tumor cell survival. Cancer Cell. 2009; 15:489-500. doi: 10.1016/j.ccr.2009.03.022.

14. Scholl C, Fröhling S, Dunn IF, Schinzel AC, Barbie DA, Kim SY, Silver SJ, Tamayo P, Wadlow RC, Ramaswamy S, Döhner K, Bullinger L, Sandy P, et al. Synthetic lethal interaction between oncogenic KRAS dependency and STK33 suppression in human cancer cells. Cell. 2009; 137:821-34. doi: 10.1016/j.cell.2009.03.017.

15. Jackson AL, Bartz SR, Schelter J, Kobayashi SV, Burchard J, Mao M, Li B, Cavet G, Linsley PS. Expression profiling reveals off-target gene regulation by RNAi. Nat Biotechnol. 2003; 21:635-37. doi: 10.1038/nbt831.

16. Franceschini A, Meier R, Casanova A, Kreibich S, Daga N, Andritschke D, Dilling S, Rämö P, Emmenlauer M, Kaufmann A, Conde-Álvarez R, Low SH, Pelkmans L, et al. Specific inhibition of diverse pathogens in human cells by synthetic microRNA-like oligonucleotides inferred from RNAi screens. Proc Natl Acad Sci USA. 2014; 111:4548-53. doi: 10.1073/pnas.1402353111.

17. Birmingham A, Selfors LM, Forster T, Wrobel D, Kennedy CJ, Shanks E, Santoyo-Lopez J, Dunican DJ, Long A, Kelleher D, Smith Q, Beijersbergen RL, Ghazal P, et al. Statistical methods for analysis of high-throughput RNA interference screens. Nat Methods. 2009; 6:569-75. doi: 10.1038/nmeth.1351.

18. Pihur V, Datta S, Datta S. RankAggreg, an R package for weighted rank aggregation. BMC Bioinformatics. 2009; 10:62. doi: 10.1186/1471-2105-10-62.

19. Luo B, Cheung HW, Subramanian A, Sharifnia T, Okamoto M, Yang X, Hinkle G, Boehm JS, Beroukhim R, Weir BA, Mermel C, Barbie DA, Awad T, et al. Highly parallel identification of essential genes in cancer cells. Proc Natl Acad Sci USA. 2008; 105:20380-85. doi: 10.1073/ pnas.0810485105.

20. König R, Chiang CY, Tu BP, Yan SF, DeJesus PD, Romero A, Bergauer T, Orth A, Krueger U, Zhou Y, Chanda SK. A probability-based approach for the analysis of large-scale RNAi screens. Nat Methods. 2007; 4:847-49. doi: $10.1038 /$ nmeth 1089 .

21. Hanahan D, Weinberg RA. Hallmarks of cancer: the next generation. Cell. 2011; 144:646-74. doi: 10.1016/j. cell.2011.02.013.
22. Safran M, Dalah I, Alexander J, Rosen N, Iny Stein T, Shmoish M, Nativ N, Bahir I, Doniger T, Krug H, SirotaMadi A, Olender T, Golan Y, et al. GeneCards Version 3: the human gene integrator. Database (Oxford). 2010; 2010.

23. Schaaf G, Hamdi M, Zwijnenburg D, Lakeman A, Geerts D, Versteeg R, Kool M. Silencing of SPRY1 triggers complete regression of rhabdomyosarcoma tumors carrying a mutated RAS gene. Cancer Res. 2010; 70:762-71. doi: 10.1158/0008-5472.CAN-09-2532.

24. Cerami E, Gao J, Dogrusoz U, Gross BE, Sumer SO, Aksoy BA, Jacobsen A, Byrne CJ, Heuer ML, Larsson E, Antipin Y, Reva B, Goldberg AP, et al. The cBio cancer genomics portal: an open platform for exploring multidimensional cancer genomics data. Cancer Discov. 2012; 2:401-04. doi: 10.1158/2159-8290.CD-12-0095.

25. Gao J, Aksoy BA, Dogrusoz U, Dresdner G, Gross B, Sumer SO, Sun Y, Jacobsen A, Sinha R, Larsson E, Cerami E, Sander C, Schultz N. Integrative analysis of complex cancer genomics and clinical profiles using the cBioPortal. Sci Signal. 2013; 6:pl1. doi: 10.1126/ scisignal.2004088.

26. Giannakis $\mathrm{M}, \mathrm{Mu} \mathrm{X}$, Shukla $\mathrm{S}$, Qian $\mathrm{Z}$, Cohen O, Nishihara R, Bahl S, Cao Y, Amin-Mansour A, Yamauchi M, Sukawa Y, Stewart C, Rosenberg M, et al. Genomic Correlates of Immune-Cell Infiltrates in Colorectal Carcinoma. Cell Reports. 2016; 15:857-65. doi: 10.1016/j. celrep.2016.03.075.

27. Seshagiri S, Stawiski EW, Durinck S, Modrusan Z, Storm EE, Conboy CB, Chaudhuri S, Guan Y, Janakiraman V, Jaiswal BS, Guillory J, Ha C, Dijkgraaf GJ, et al. Recurrent R-spondin fusions in colon cancer. Nature. 2012; 488:660-64. doi: 10.1038/nature11282.

28. Brannon AR, Vakiani E, Sylvester BE, Scott SN, McDermott G, Shah RH, Kania K, Viale A, Oschwald DM, Vacic V, Emde AK, Cercek A, Yaeger R, et al. Comparative sequencing analysis reveals high genomic concordance between matched primary and metastatic colorectal cancer lesions. Genome Biol. 2014; 15:454. doi: 10.1186/s13059014-0454-7.

29. Muzny DM, Bainbridge MN, Chang $\mathrm{K}$, Dinh $\mathrm{HH}$, Drummond JA, Fowler G, Kovar CL, Lewis LR, Morgan MB, Newsham IF, Reid JG, Santibanez J, Shinbrot E, et al, and Cancer Genome Atlas Network. Comprehensive molecular characterization of human colon and rectal cancer. Nature. 2012; 487:330-37. doi: 10.1038/ nature 11252.

30. The Cancer Genome Atlas - Data Portal. URL https://tcgadata.nci.nih.gov/docs/publications/tcga/.

31. Biankin AV, Waddell N, Kassahn KS, Gingras MC, Muthuswamy LB, Johns AL, Miller DK, Wilson PJ, Patch AM, Wu J, Chang DK, Cowley MJ, Gardiner BB, et al, and Australian Pancreatic Cancer Genome Initiative. Pancreatic cancer genomes reveal aberrations in axon guidance pathway genes. Nature. 2012; 491:399-405. doi: 10.1038 /nature 11547 . 
32. Witkiewicz AK, McMillan EA, Balaji U, Baek G, Lin WC, Mansour J, Mollaee M, Wagner KU, Koduru P, Yopp A, Choti MA, Yeo CJ, McCue P, et al. Whole-exome sequencing of pancreatic cancer defines genetic diversity and therapeutic targets. Nat Commun. 2015; 6:6744. doi: $10.1038 /$ ncomms 7744 .

33. Bailey P, Chang DK, Nones K, Johns AL, Patch AM, Gingras MC, Miller DK, Christ AN, Bruxner TJ, Quinn MC, Nourse C, Murtaugh LC, Harliwong I, et al, and Australian Pancreatic Cancer Genome Initiative. Genomic analyses identify molecular subtypes of pancreatic cancer. Nature. 2016; 531:47-52. doi: 10.1038/nature16965.

34. Weidle UH, Maisel D, Eick D. Synthetic lethality-based targets for discovery of new cancer therapeutics. Cancer Genomics Proteomics. 2011; 8:159-71.

35. Yang A, Rajeshkumar NV, Wang X, Yabuuchi S, Alexander BM, Chu GC, Von Hoff DD, Maitra A, Kimmelman AC. Autophagy is critical for pancreatic tumor growth and progression in tumors with p53 alterations. Cancer Discov. 2014; 4:905-13. doi: 10.1158/2159-8290. CD-14-0362.

36. Tanida I, Ueno T, Kominami E. LC3 and Autophagy. Methods Mol Biol. 2008; 445:77-88. doi: 10.1007/978-159745-157-4_4.

37. Razi M, Chan EY, Tooze SA. Early endosomes and endosomal coatomer are required for autophagy. J Cell Biol. 2009; 185:305-21. doi: 10.1083/jcb.200810098.

38. Claerhout S, Dutta B, Bossuyt W, Zhang F, NguyenCharles C, Dennison JB, Yu Q, Yu S, Balázsi G, Lu Y, Mills GB. Abortive autophagy induces endoplasmic reticulum stress and cell death in cancer cells. PLoS One. 2012; 7:e39400. doi: 10.1371/journal.pone.0039400.

39. Burada F, Nicoli ER, Ciurea ME, Uscatu DC, Ioana M, Gheonea DI. Autophagy in colorectal cancer: an important switch from physiology to pathology. World J Gastrointest Oncol. 2015; 7:271-84. doi: 10.4251/wjgo.v7.i11.271.

40. Sakitani K, Hirata Y, Hikiba Y, Hayakawa Y, Ihara S, Suzuki H, Suzuki N, Serizawa T, Kinoshita H, Sakamoto K, Nakagawa H, Tateishi K, Maeda S, et al. Inhibition of autophagy exerts anti-colon cancer effects via apoptosis induced by p53 activation and ER stress. BMC Cancer. 2015; 15:795. doi: 10.1186/s12885-015-1789-5.

41. Ward AF, Braun BS, Shannon KM. Targeting oncogenic Ras signaling in hematologic malignancies. Blood. 2012; 120:3397-406. doi: 10.1182/blood-2012-05-378596.
42. van Dam EM, Robinson PJ. Ral: mediator of membrane trafficking. Int J Biochem Cell Biol. 2006; 38:1841-47. doi: 10.1016/j.biocel.2006.04.006.

43. Mitchell A, Chang HY, Daugherty L, Fraser M, Hunter S, Lopez R, McAnulla C, McMenamin C, Nuka G, Pesseat S, Sangrador-Vegas A, Scheremetjew M, Rato C, et al. The InterPro protein families database: the classification resource after 15 years. Nucleic Acids Res. 2015; 43:D213-21. doi: 10.1093/nar/gku1243.

44. Hernandez-Valladares M, Prior IA. Comparative proteomic analysis of compartmentalised Ras signalling. Sci Rep. 2015; 5:17307. doi: 10.1038/srep17307.

45. Ihle NT, Byers LA, Kim ES, Saintigny P, Lee JJ, Blumenschein GR, Tsao A, Liu S, Larsen JE, Wang J, Diao L, Coombes KR, Chen L, et al. Effect of KRAS oncogene substitutions on protein behavior: implications for signaling and clinical outcome. J Natl Cancer Inst. 2012; 104:228-39. doi: 10.1093/jnci/djr523.

46. Deer EL, González-Hernández J, Coursen JD, Shea JE, Ngatia J, Scaife CL, Firpo MA, Mulvihill SJ. Phenotype and genotype of pancreatic cancer cell lines. Pancreas. 2010; 39:425-35. doi: 10.1097/MPA.0b013e3181c15963.

47. Singh A, Sowjanya AP, Ramakrishna G. The wild-type Ras: road ahead. FASEB J. 2005; 19:161-69. doi: 10.1096/fj.042584hyp.

48. Kim HS, Mendiratta S, Kim J, Pecot CV, Larsen JE, Zubovych I, Seo BY, Kim J, Eskiocak B, Chung H, McMillan E, Wu S, De Brabander J, et al. Systematic identification of molecular subtype-selective vulnerabilities in non-small-cell lung cancer. Cell. 2013; 155:552-66. doi: 10.1016/j.cell.2013.09.041.

49. Unniyampurath U, Pilankatta R, Krishnan MN. RNA Interference in the Age of CRISPR: Will CRISPR Interfere with RNAi? Int J Mol Sci. 2016; 17:291. doi: 10.3390/ ijms 17030291.

50. Dwork C, Kumar R, Naor M, Sivakumar D. Rank Aggregation Revisited. Syst Res. 2001; 13:86-93.

51. Rückert F, Aust D, Böhme I, Werner K, Brandt A, Diamandis EP, Krautz C, Hering S, Saeger HD, Grützmann R, Pilarsky C. Five primary human pancreatic adenocarcinoma cell lines established by the outgrowth method. J Surg Res. 2012; 172:29-39. doi: 10.1016/j. jss.2011.04.021. 